\title{
PREVALENCE AND DETERMINANTS OF MALE CONDOM UTILIZATION IN ONDO STATE NIGERIA
}

\author{
Olayinka Stephen Ilesanmi*, Faith Osaretin Alele**
}

\author{
Corresponding author: Olayinka Stephen Ilesanmi - ileolasteve@yahoo.co.uk \\ *Department of Community Health, Federal Medical Centre, Owo, Ondo State, Nigeria \\ **Department of Community Health, Federal Medical Centre, Owo, Ondo State, Nigeria
}

\begin{abstract}
A B S T R A C T
Introduction: Male condom use has been advocated to prevent unwanted pregnancy and Sexually Transmitted Infections (STI). Predictors of condom use will help in understanding groups requiring more interventions. This study aims at determining the prevalence and predictors of male condom utilization in Ondo State. Methods: This is a secondary data analysis of the Nigeria National Demographic and Health Survey (NDHS) 2013 data set. Ondo state data was extracted. The study area was Ondo State, Nigeria. It was a descriptive cross-sectional study and it focused on men between ages 15-49 years. Descriptive statistics were done. Data was analysed using Chi-square test and logistic regression. Level of statistical significance was $p<0.05$. Results: The mean age of the 404 respondents was $29 \pm 10$ years, $215(53.2 \%)$ were never in a marital union, $258(63.8 \%)$ had secondary level of education. Out of $318(78.7 \%)$ respondents who have ever had sex $91(28.7 \%)$ used condom at last sex. In age 15-24 categories $37(59.7 \%)$ used condoms while only $54(24.7 \%)$ used among respondents above 25 years, $\mathrm{p}<0.001$. Among those who were never in any marital union $58(60.4 \%)$ used condom compared to $13(22.8 \%)$ of those who were living with partners, $p<0.001$. Men who were not in union had about 4 times odds of using condoms (OR 3.6, 95\% Cl: 1.5-8.7, $\mathrm{p}=0.004$ ). Conclusion: To reduce the prevalence of HIV/AIDS and transmission of STI emphasis needs to be put on the use of condom. Effort at promoting condom use should be encouraged among men in marital union especially those having extramarital sex.
\end{abstract}

Key words: Condoms, HIV, STI, Sexual Behavior 
Condom use during a sexual act has been shown to reduce, the chances of infection like HIV and other sexually transmitted diseases (STDs) and the chances of becoming pregnant ${ }^{1-3}$. The promotion and distribution programs of condoms have grown significantly over the past decades. Globally, it has been shown that both the male and female latex condoms are highly effective and efficient in the reduction of sexual transmission of HIV and other sexually transmitted infections ${ }^{4}$.

The mechanism of action is by preventing the transfer of fluids between sexual partners such semen, anal mucosa, menstrual blood and vaginal mucous fluid ${ }^{5}$. Some studies have shown that latex and polyurethane condoms provide an impermeable barrier to HIV, STDs, and also increase the clearance rate of human papillomavirus (HPV) and cervical intraepithelial neoplasia $(\mathrm{CIN})$ regression ${ }^{6,7}$. The male condom is cost effective, easy to access, simple to dispose and its non-systemic action with minimal side effect has made it an effective means of birth control when used consistently and correctly ${ }^{8}$.

Among adolescents prevalence of condom use was $30 \%$ in a Nigerian study, among HIV-positive patients the prevalence of condom use in the last sexual act was $30.5 \%$. Teenagers and the elderly, and less educated were more likely to engage in unprotected $\operatorname{sex}^{2,9}$. A trend analysis by Global AIDS Response Country Progress Report (GARPR) revealed that, young people aged $15-24$ years had HIV prevalence of $4.3 \%$ in $2005,4.2 \%$ in 2008 and $4.2 \%$ in $2010^{10}$.

Several factors affect the correct and consistent use of condoms; among male teenagers and young adults in a study conducted in Angola, consistent use of condom was positively associated with higher level of education, believing that condoms were safe, having multiple partners and with the belief that condoms did not diminish sexual pleasure ${ }^{11}$. Other factors include, the type of sexual partner whether casual or regular, correct and reliable reproductive health information, accessibility to health facilities, operating hours and issues of confidentiality and availability of condoms ${ }^{12}$. In a survey conducted in Nigeria, condom use was very low at $25 \%$ among sexually active males ${ }^{13}$.

Most studies have neglected all sexually active men. A lot were done among adolescent while many others were among HIV positive clients. The use of condom is not spontaneous it has been suggested that condom use is determined by the social context within which the sexual behavior occurs ${ }^{14,15}$. Hence the study of the sociodemographic determinants of condom use will help in understanding who are likely to use condom and who are not. Though the NDHS was conducted nationally, a subnational analysis can help to guide local decision making. This study aimed at determining the prevalence and predictors of male condom utilization in Ondo State Nigeria.

\section{METHODS}

This is a secondary data analysis of the Nigeria NDHS 2013 data set. The 2013 Nigeria NDHS is a national sample survey that provides up-to-date information on background characteristics of the respondents. Specifically, information is collected on fertility levels, marriage, fertility preferences, awareness and the use of family planning methods, child feeding practices, nutritional status of women and children, adult and childhood mortality, awareness and attitudes regarding HIV/AIDS, female genital mutilation, and domestic violence. The target groups were women and men age 1549 in randomly selected households across Nigeria. Information was also collected on the height and weight of women and children age 0-5. In addition to presenting national estimates, the report provides estimates of key indicators for both the rural and urban areas in Nigeria, the six geo-political zones, the 36 states, and the Federal Capital Territory (FCT).

Nigeria NDHS 2013 is the fourth survey of its kind to be implemented by the National Population Commission (NPC). The collection and analyses of the data was done by the NPC. The data was however made available for those who are willing to reanalyse. This was aimed at assisting policymakers 
and program managers in monitoring and designing programs and strategies for improving health and family planning services in Nigeria.

The study was done in Ondo State, South West Nigeria. A descriptive cross-sectional design was used. Men between ages 15-49 years were the studied population. National sample was gotten through multistage sampling in the six geo-political zones and the FCT. Data was downloaded in SPSS format. The data for Ondo State was selected and saved separately. The Nigeria NDHS has more than one hundred different variables on men, women, as well as children. To determine the prevalence and predictors of male condom utilization in Ondo State Nigeria independent variables selected from the large NDHS data set were current age, age group in 5 categories, type of residence, level of education, religion, current marital status, wealth index, and recent sexual activity. The dependent variable was condom use at last sex with most recent partner. Descriptive statistics was done and presented in tables and figures. Bivariate analysis (Chi-square test) was used to compare sociodemographic characteristics with condom use. Variables significant at bivariate analysis were used in the logistic regression model to identify the predictors of condom use.
Permission for the secondary analysis was obtained from Demographic Health Survey, USA. In the Nigeria NDHS 2013 survey, consent was received from participants. Voluntariness and confidentiality was ensured. No obvious harm came to the participants.

\section{RESULTS}

The mean age of respondent was 29 years \pm 10 standard deviation. The median age is 28 years (range 15-49 years). Table 1 shows the Sociodemographic characteristics of male respondents in Ondo State, NDHS 2013. Respondents aged 15-24 years were $161(39.8 \%)$, Almost half $215(53.2 \%)$ were never in a marital union. Concerning religion Catholic were 26(6.4\%), other Christians were 302(74.7\%) while Islam were $76(18.9 \%)$. The educational status of $258(63.8 \%)$ was secondary while only $6(1.5 \%)$ had no formal education. The wealth index was computed using the possession of household items 101(5\%) were in each category. Other sociodemographic characteristics are shown in table 1.

Table 1. Sociodemographic characteristics of male respondents in Ondo State, NDHS 2013

\begin{tabular}{|c|c|c|}
\hline Characteristics & Frequency $n=404$ & Percent \\
\hline \multicolumn{3}{|l|}{ Age group in years } \\
\hline $15-24$ & 161 & 39.8 \\
\hline$>24$ & 243 & 60.2 \\
\hline \multicolumn{3}{|l|}{ Place of residence } \\
\hline Urban & 218 & 54.0 \\
\hline Rural & 186 & 46.0 \\
\hline \multicolumn{3}{|l|}{ Current marital status } \\
\hline Never in union & 215 & 53.2 \\
\hline Married & 130 & 32.1 \\
\hline Living with partner & 60 & 14.8 \\
\hline \multicolumn{3}{|l|}{ Religion } \\
\hline Catholic & 26 & 6.4 \\
\hline Other Christian & 302 & 74.7 \\
\hline Islam & 76 & 18.9 \\
\hline \multicolumn{3}{|l|}{ Educational Status } \\
\hline No formal education & 6 & 1.5 \\
\hline Primary & 57 & 14.0 \\
\hline Secondary & 258 & 63.8 \\
\hline Higher & 83 & 20.7 \\
\hline \multicolumn{3}{|l|}{ Wealth Index } \\
\hline Poorer & 101 & 24.9 \\
\hline Middle & 101 & 25.0 \\
\hline Richer & 101 & 25.1 \\
\hline Richest & 101 & 25.0 \\
\hline
\end{tabular}


Among the 404 respondents $318(78.7 \%)$ had ever had sex, while $86(21.3 \%)$ never had sex. Out of the $318(78.7 \%)$ that have had sex $190(59.8 \%)$ did not use condom at last sex, while only $91(28.7 \%)$ used. Also, $36(11.5 \%)$ did not give any response. The prevalence of male condom use in Ondo State Nigeria is $28.7 \%$. Figure 1 shows that condom use was in $14(63.6 \%)$ of respondent age 15-19 years while only $2(5.6 \%)$ used condom at last sex among respondent age $40-44$ years.

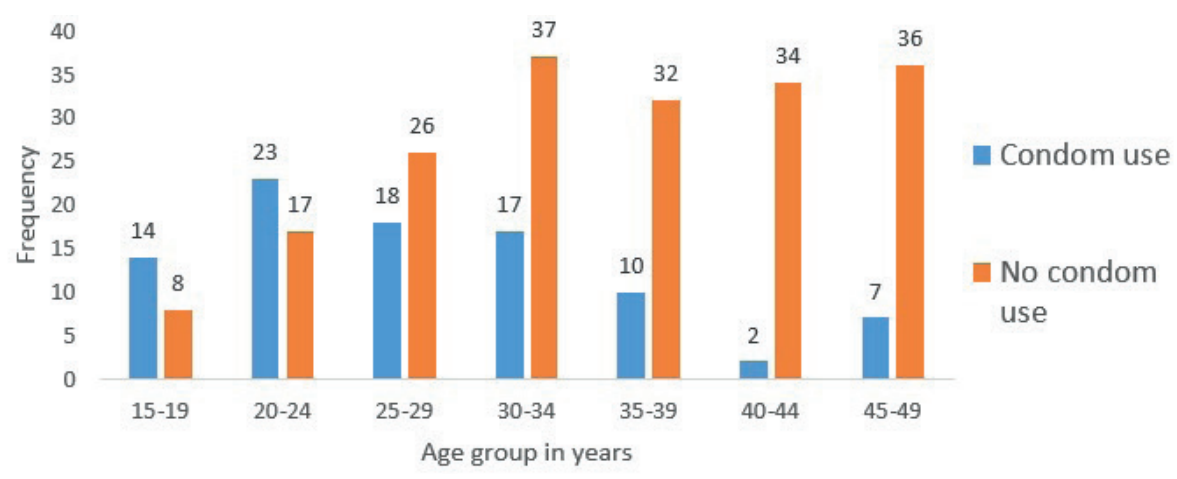

Figure 1: Age group and Male condom use in Ondo State, Nigeria $\mathrm{X} 2=41.154, \mathrm{p}<0.001$

Table 2 shows the association between sociodemographic characteristics and male condom use in Ondo State. In age 15-24 categories $37(59.7 \%)$ used condoms while only $54(24.7 \%)$ used among respondents above 25 years, $\mathrm{p}<0.001$. with regards to current marital status $58(60.4 \%)$ used condom among those who were never in any marital union compared to $13(22.8 \%)$ of those who were living with partners, this association was statistically significant $p<0.001$. concerning level of education 29(45.35) of respondent with higher education used condom compare to $9(19.1 \%)$ of respondents with primary education, $p=0.001$. The use of condom was not affected by wealth index.

Table 2. Association between sociodemographic characteristics of male respondents in Ondo State and Condom use, NDHS 2013

\begin{tabular}{|c|c|c|c|c|}
\hline \multirow[t]{2}{*}{ Characteristics } & \multicolumn{2}{|c|}{ Condom use at last sex } & \multirow[b]{2}{*}{ Chi square } & \multirow[b]{2}{*}{ p-value } \\
\hline & $\begin{array}{c}\text { Yes } \\
n(\%)\end{array}$ & $\begin{array}{c}\text { No } \\
n(\%)\end{array}$ & & \\
\hline \multicolumn{5}{|l|}{ Age group in years } \\
\hline $15-24$ & $37(59.7)$ & $25(40.3)$ & 27.16 & $<0.001$ \\
\hline$>24$ & $54(24.7)$ & $165(75.3)$ & & \\
\hline \multicolumn{5}{|l|}{ Place of residence } \\
\hline Urban & $55(32.8)$ & $89(61.8)$ & 4.55 & 0.033 \\
\hline Rural & $36(26.3)$ & $101(73.7)$ & & \\
\hline \multicolumn{5}{|l|}{ Current marital status } \\
\hline Never in union & $58(60.4)$ & $38(39.6)$ & 51.91 & $<0.001$ \\
\hline Married & $21(16.3)$ & 108(83.7) & & \\
\hline Living with partner & $13(22.8)$ & $44(77.2)$ & & \\
\hline \multicolumn{5}{|l|}{ Religion } \\
\hline Catholic & $9(47.4)$ & $10(52.6)$ & 2.28 & 0.321 \\
\hline Other Christian & $66(32.4)$ & $138(67.6)$ & & \\
\hline Islam & $17(28.8)$ & $42(71.2)$ & & \\
\hline \multicolumn{5}{|l|}{ Level of Education } \\
\hline No formal education & $0(0)$ & $6(100)$ & 11.396 & 0.001 \\
\hline Primary & $9(19.1)$ & $38(80.9)$ & & \\
\hline Secondary & $53(32.3)$ & $111(67.7)$ & & \\
\hline Higher & $29(45.3)$ & $35(54.7)$ & & \\
\hline \multicolumn{5}{|l|}{ Wealth Index } \\
\hline Poorer & $17(23.0)$ & $57(77.0)$ & 4.422 & 0.219 \\
\hline Middle & $24(38.7)$ & $38(61.3)$ & & \\
\hline Richer & $25(34.2)$ & $48(65.8)$ & & \\
\hline Richest & $25(34.7)$ & $47(65.3)$ & & \\
\hline
\end{tabular}


Table 3 shows the sociodemographic determinants of male condom use in Ondo State, Nigeria using the NDHS 2013 data set. Men who were not in union had about 4 times odds of using condoms (OR 3.6, 95\% Cl: 1.5-8.7, $\mathrm{p}=0.004)$.

Table 3. Sociodemographic determinants of male condom use in Ondo State, Nigeria NDHS 2013

\begin{tabular}{|c|c|c|c|c|}
\hline \multirow[t]{2}{*}{ Characteristics } & \multirow[t]{2}{*}{$\begin{array}{l}\text { Odds } \\
\text { ratio }\end{array}$} & \multicolumn{2}{|c|}{$\begin{array}{l}95 \% \text { Confidence interval } \\
\text { of odds ratio }\end{array}$} & \multirow[t]{2}{*}{ p-value } \\
\hline & & Lower & Upper & \\
\hline \multicolumn{5}{|l|}{ Age group in years } \\
\hline $15-24$ & 1.57 & 0.710 & 3.474 & 0.256 \\
\hline$>24$ & 1 & & & \\
\hline \multicolumn{5}{|l|}{ Place of residence } \\
\hline Urban & 1.5 & 0.713 & 3.167 & 0.285 \\
\hline Rural & 1 & & & \\
\hline \multicolumn{5}{|l|}{ Current marital status } \\
\hline Never in union & 3.63 & 1.518 & 8.665 & 0.004 \\
\hline Married & 0.6 & 0.261 & 1.378 & 0.229 \\
\hline Living with partner & 1 & & & \\
\hline \multicolumn{5}{|l|}{ Level of Education } \\
\hline No formal education & 0.000 & 0.000 & $\infty$ & 0.999 \\
\hline Primary & 0.462 & 0.161 & 1.321 & 0.150 \\
\hline Secondary & 0.510 & 0.251 & 1.035 & 0.062 \\
\hline Higher & 1 & & & \\
\hline
\end{tabular}

\section{DISCUSSION}

The prevalence and predictors of condom use in Ondo State Nigeria was done by analysing NDHS, 2013 data set. Condom use has been showed to bring about a drastic reduction in the prevalence of HIV and with the current prevalence of HIV in Nigeria at $3.2 \%$, a high prevalence rate of condom use is expected ${ }^{16}$. The prevalence of condom use in Ondo State Nigeria is $28.7 \%$. This prevalence is low despite the increasing prevalence of HIV. The reason for this might be as a result of inconsistent and a high discontinuation rate of the use of condoms by couples. The unending need for procreation, experimentation with the method and misunderstanding about the need and importance of consistent condom use has led to this inconsistency and high discontinuation rate ${ }^{17}$. Male condom was used as a form of contraceptive in the late 1990s by $4.9 \%$ of the world's married couple and the highest prevalence rate was found in Japan, however, many developing countries still recorded a low condom use prevalence rate ${ }^{18,19}$. Recent studies have shown that condom use has risen in many countries as a result of the increased awareness of the detrimental effect of unprotected $\operatorname{sex}^{20}$.

Young people used male condom during the last sex compared to the middle-aged and older age group in the studied population, this is most likely as a result of the increased awareness on condom use, rising prevalence of HIV and the older age group are likely to be faithful to their sexual partner compared to the young ones. This is in contrast to a study conducted among Nigerian soldiers in llorin where condom use among respondents within the age range 18-34 years was reportedly low ${ }^{21}$. Another study conducted among clients visiting $\mathrm{HCT}$ center at Ogun state was at discordance with the finding of this study, where low use of condom among the younger clients was also reported ${ }^{22}$. A higher proportion of those who had never been in any marital union were recorded to have used a condom during their most recent sexual act compared to those who were married or living with a partner. The increase attention and publicity given to the use of condom among age group 18 to 34 years who are increasingly mobile, prone to risky sexual behavior and substance use 
is probably responsible for the increased usage though they are vulnerable. However, other studies showed low condom use during the last sexual intercourse among younger age group compared to their married counterparts ${ }^{22,23}$. Despite increased awareness of HIV infection, condom use in Nigeria remains alarming low even among people living with $\mathrm{HIV}^{24}$. Other factors significantly related to condom use during the last sexual intercourse were increasing level of literacy and richer wealth index. It is expected that those with higher level of education should engage in less risky sexual behavior than the less educated. This finding is in agreement with a study where condom use was higher among respondents with secondary education ${ }^{21}$. Condom use among the educated may be different from those with little or no formal education. Level of education has been identified as a determinant of increased condom use in non-marital relationship ${ }^{25}$. On the contrary, higher level of education was found to be related to non-use of condoms during the most recent act of sexual intercourse in a particular study ${ }^{22}$. Condom use during last sex was increased among the richer wealth index in this study was corroborated by findings from other studies in Ibadan and also Lusaka which reported that condom use increased with improved socio economic status ${ }^{26,27}$.

Those who were not married or in any union were 4 times more likely to use a condom during sexual intercourse compared to their married counterparts. This shows that those who are married are not inclined towards using condoms during sexual intercourse. A study conducted among Nigerian youths using the NARHS 2007 data survey set also reported that youths who were not in any union were more likely to use condoms during sexual intercourse compared to those who were married ${ }^{28}$.

According to studies conducted in Nigeria, condom use was more common non marital relationships than in marital contexts, while in Lusaka, those who were not in any union or marital relationship were eight times more likely to use condoms than those in marital relationships ${ }^{26,29}$.

\section{LIMITATION}

Findings from this study though corroborated by other studies has some limitations first it was not possible to know if the reason for non-use of condom is to achieve pregnancy among married couples. Also, all the respondents had sex with women. It was not possible to find out the difference in condom use between men who had sex with men and men who had sex with women and men who had sex with men and women.

\section{CONCLUSION}

To reduce the prevalence of STI, HIV/AIDS emphasis needs to be put on the use of condom. The significant predictor of condom use is being a single (never in union). Though the use of condom among single is usually given wide publicity. The finding is not surprising since low condom use has been reported among married couple. There is a need to promote condom use even among married couples. Effort at promoting condom use should not be limited to the adolescent alone. It should be encouraged among men in marital union especially those having extramarital sex.

\section{CONFLICT OF INTEREST}

The authors declare that no conflict of interest exists.

\section{REFERENCES}

1. Koeng M, Zablotska I, Lutalo T, Nalugoda F, Wagman J, Gray R. Coerced first intercourse and reproductive health among adolescent women in Rakai, Uganda. Int Fam Plan Perspect. 2004;30(4):156-163. doi: 10.1363/ ifpp.30.156.04 
2. Sabageh $A O$, Fatusi $A O$, Sabageh $D$,

Babatunde OA. Condom Use: Prevalence among Rural and Urban Sexually Active Adolescents in Osun state, Nigeria. Science Journal of Public Health. 2014;2(4):270-274. doi: 10.11648/i. siph.20140204.14

3. Tarkang EE. Predictors of Consistent Condom Use among Secondary School Male Students in Mbonge Subdivision of Rural Cameroon. Science Journal of Public Health. 2013;1(4):165-174. doi: $10.11648 /$ i.sjph.20130104.11

4. UNFPA. Delivering Results, 2011 Annual Report in a World of 7 Billion [Internet]. 2011 [cited 10/07/2015]. Available from: http://www.unfpa. org/sites/default/files/pub-pdf/

5. Dodds C. Male condom use among African people in England. London: Sigma Research. BASS line 2009 [Internet]. 2010 [cited 10/07/2015]. Available from: http://kwp.org.uk/files/kwpbriefing 1.pdf

6. CDC. Condom Fact Sheet In Brief 2013 [Internet]. 2015 [cited 24/10/2015]. Available from: http://www.cdc.gov/condomeffectiveness/ brief.html

7. Clinical Effectiveness Unit. Barrier methods of contraception and STI prevention. Faculty of Sexual and Reproductive HealthCare (FSRH); 2012

8. Trussell J. Contraceptive failure in the United States. Contraception. 2011 ;83(5):397-404. doi: 10.1016/i.contraception.2011.01.021

9. Amoran O, Ladi-Akinyemi T. Sexual Risk History and Condom Use among People Living with HIV/ AIDS in Ogun State, Nigeria. The Journal of Sexual Medicine. 2012;9(4):997-1004. doi: $10.1111 / \hat{j} .1743-6109.2011 .02602 . x$

10. NACA. Global AIDS response country progress report [Internet]. 2012 [cited 20/7/2015]. Available from: http://www. unaids.org/en/dataanalysis/knowyourresponse/ countryprogressreports/2012countries/ Nigeria $\% 20201$ 2\%20GARPR\%20Report $\% 20$ Revised.pdf
11. Prata N, Vahidnia F, Fraser A. Gender and relationship differences in condom use among 15-24-year-olds in Angola. Int Fam Plan Perspect. 2005;31(4):192-199. doi: 10.1363/ ifpp.31.192.05

12. Douthwaite M, Saroun L. Sexual behaviour and condom use among unmarried young men in Cambodia. AIDS Care. 2006;18(5):505-513. doi: $10.1080 / 13548500500221537$

13. Federal Ministry of Health. HIV Integrated Biological and Behavioural Surveillance Survey. Nigeria Integrated Biological and Behavioural Surveillance Survey. 2010

14. Gupta G, Parkhurst J, Ogden J, Aggleton P, Mahal A. Structural approaches to HIV prevention. Lancet. 2008;372(9640):764-775. doi: 10.1016/ S0140-6736(08)60887-9

15. Shannon K, Strathdee S, Shoveller J, Rusch M, Kerr T, Tyndall MW. Structural and environmental barriers to condom use negotiation with clients among female sex workers: Implications for HIVprevention strategies and policy. Am J Public Health. 2009;99(4):659-665. doi: 10.2105/ AJPH.2007.129858

16. UNAIDS. AIDs info [Internet]. 2014 [cited $21 / 7 / 2015]$. Available from: http://aidsinfo. unaids.org

17. Smith JD. Premarital Sex, Procreation and HIV Risk in Nigeria. Studies in Family Planning. 2004;35(4):223-235. doi: 10.1111 /i.00393665.2004.00027.x

18. United Nations. Levels and Trends of Contraceptive Use [Internet]. 2013 [cited 21 /7/2015]. Available from: http://www.un.org/ en/development/desa/population/theme/familyplanning/index.shtml

19. Engender Health. Contraceptive Sterilization: Global Issues and Trends. New York: 2002

20. Andrzeji K. Socio-cultural context of condom use within marriage in Rural Lebanon. Stud. Family Plan. 2004;35(4):246-260 
21. Hussain NA, Akande TM. Sexual behaviour and condom use among Nigerian soldiers in llorin, Kwara state, Nigeria. Afr. J. Cln. Exper. Microbiol. 2009;10(2):1 28-135. doi: 10.4314/ajcem. v10i2.7514

22. Olowookere SA, Adeleke NA, Fatiregun AA, Abioye-Kuteyi EA. Pattern of condom use among clients at a Nigerian HIV Counseling and Testing Centre. BMC Research Notes. 2013;6:289. doi: 10.1186/1756-0500-6-289

23. Williamson NE, Liku J, McLoughlin K, Nyamongo I, Nakayima F. A qualitative study of condom use among married couples in Kampala, Uganda. Reprod Health Matters. 2006; 1 4(28):89-98. doi: $10.1016 /$ S0968-8080(06)28268-5

24. Denue BA, Kwayabura SA, Bukbuk D, Inuwa $U$, Ajayi BB. Evaluation of Condom Use and Associated Factors among Adult HIV Clients in Maiduguri, North Eastern Nigeria: A Comparative Cross Sectional Study. World Journal of AIDS. 2014;4(2):169-177. doi: 10.4236/ wja.2014.42022

25. Lagarde E, Carael M, Glynn J, Kanhonou $L$, Abega $S$, Kahindo M. Educational level is associated with condom use within non-spousal partnerships in four cities of sub-Saharan Africa. AIDS. $2001 ; 15(11): 1399-1408$

26. Agha S. Patterns of use of the female condoms after one year of mass marketing. AIDS Educ Prev. $2001 ; 13(1): 55-64$

27. Sunmola A, Olley BO, Oso GE. Predictors of condom use among sexually active persons involved in compulsory national service in Ibadan, Nigeria. Health Education Research Journal. 2007;22(4):459-472. doi: 10.1093/her/cyl100

28. Ayoola FJ, Oshodi OC. On the Comparative Analysis of Determinant Factors on the use of Condom among Nigerian Youths. Global Journal of Medical Research Interdisciplinary. 2013;13(6):1-8

29. Messersmith LJ, Kane TT, Odebiyi Al, Adewuyi AA. Who's at risk? Men's STD experience and condom use in southwest Nigeria. Stud Fam Plann. 2000;31(3):203-216 